\title{
Enhancement of Plant Growth, Nodulation and Yield of Mungbean (Vigna radiate L.) by Microbial Preparations
}

\author{
Farrukh Matkarimov $^{1,2}$, Dilfuza Jabborova ${ }^{1} *$ and Saidmurot Baboev $^{1}$ \\ ${ }^{1}$ Institute of Genetics and Plant Experimental Biology, Academy of Sciences of Uzbekistan, \\ Kibray 111226, Tashkent region, Uzbekistan \\ ${ }^{2}$ Chirchik State Pedagogical Institute of Tashkent region \\ *Corresponding author
}

\section{Keywords \\ Mungbean, \\ Microbial \\ preparations, \\ Inoculation, Plant growth, Nodulation, \\ Yield \\ Article Info \\ Accepted: \\ 20 July 2019 \\ Available Online: \\ 10 August 2019}

\section{A B S T R A C T}

\section{Introduction}

Mungbean (Vigna radiate L.) is an important legume for human nutrition and a major protein (1). Seeds contain $60-65 \%$ carbohydrates, fat (1-1.5\%) and $3.5-4.5 \%$ fibre. It plays also in enhancing the soil fertility by fixing the atmospheric nitrogen (2). Symbiotic relationships of the rhizobia also play a key role in improving the quality and productivity of the soil. Rhizobial species such as Rhizobium, Bradyrhizobium,
Sinorhizobium and Mesorhizobium are commonly used as inoculants in various parts of the world for improving the yield of legumes. When seed inoculation with Rhizobium, colonize plant roots, increase plant growth, development, noduation and yield of legume crops by multifarious mechanisms, such as control of soil borne and systemic pathogens, beneficial activities in terms of nutrients availability and production of enzymes and plant growth regulators (3-9). Environmentally, the use of specific 
rhizobium may be preferable to the use of nonspecific chemical fertilizers and pesticides because of cost, time effectiveness, and contributions to sustainable agricultural systems.

There are many reports on the positive effects of inoculation of legumes with Rhizobium spp. Several studies have shown that rhizobial inoculants increased in nodulation, $\mathrm{N}_{2}$ fixation and nitrogenize activity of nodulated legumes (10-12). The inoculation with Rhizobium spp. had enhanced nodulation and nitrogen fixation, plant biomass and grain yield in various leguminous species including mungbean, chickpea, bean and soybean (1316). Daramola et al., (17) reported that increased nodule number, nodule weight, nitrogen fixation, dry matter and nitrogen yield of soybean when inoculated with Brudyrhizobium japonicum strain.

Microbial preparations to mungbean for better plant height, root length, dry biomass, nodulation and yield components of mungbean was investigated in field conditions. The aim of this field research was to study the possibility of cultivation of mungbean by applying seed inoculation with selected highly effective microbial preparation.

\section{Materials and Methods}

Mungbean (Vigna radiate L.) seed cultivar Zilola was used for field experiments. Rhizobium 3 and Rhizobium 9 preparations were obtained from the culture collection of the Department of Microbiology and Biotechnology, National University of Uzbekistan. PlantaStim (trichodermin) was obtained from private company of AnGuzal Agroservis, Uzbekistan.

A field experiment was conducted to study effect of Rhizobium 3, Rhizobium 9 and
PlantaStim on plant growth, nodulation and yield of Mungbean (Vigna radiate L.). The experiment were carried out in randomized block design with three replications a field experiments at the Institute of Genetics and Plant Experimental Biology, Kibray, Tashkent region, Uzbekistan. Experimental treatments included of uninoculation control, inoculation with Rhizobium 3, Rhizobium 9 and PlantaStim. Seeds were sown on 13 and 14 April for the year of 2018. A plot size of 10 $\mathrm{m}^{2}$ with row spacing $30 \mathrm{~cm}$ and plant spacing of $10 \mathrm{~cm}$ were used. Harvesting was performed on 18 and 19 July 2018. After 94 and 95 days plant height, length of roots and pods, dry weight of roots, dry weight of stems, dry weight of pods, dry weight of grains, number of pods and grains per plant, number of grains per pod, 1000 grains weight were determined.

Experimental data were analysed with the StatView Software using ANOVA. The signifi cance of the effect of treatment was determined by the magnitude of the $\mathrm{F}$ value ( $\mathrm{P}$ $<0.05)$.

\section{Results and Discussion}

An effect of inoculation of mungbean seed either with Rhizobium 3, Rhizobium 9 and PlantaStim preparations on plant growth, nodulation and yield of mungbean were conducted in field conditions. The results showed that PlantaStim preparation inoculation increased dry weight of root by $15 \%$ and dry weight of shoot by $57 \%$ compared to control (Table 1). The Rhizobium 3 and Rhizobium 9 showed better results over to control and PlantaStim. Data in Table 1 indicated that Rhizobium 9 inoculation increased plant height by $27 \%$, root length by $77 \%$ and root dry weight by $78 \%$, compared to uninoculated control. When inoculation with Rhizobium 3 preparation significantly increased the plant height by $33 \%$, root length 
by $77 \%$, shoot dry weight by $32 \%$, root dry weight by $78 \%$.

Inoculation with Rhizobium preparations indicated increase in the height of plant, length of root, dry weight of root and dry weight of shoot of mungbean compared to control. There are many studies which showed that seed inoculation with Rhizobium bacteria increase the height of plant, length of root, dry weight of root and dry weight of shoot of legume crops (18-21). Similar results were obtained by Youseif et al., (22) in soybean. Delic et al., (23) reported that inoculation with bradyrhizobial strains increased shoot dry weight by $26-33 \%$ compared to control. Dhami and Prasad (24) confirmed that inoculation of effective $B$. japonicum strains significantly increased the plant biomass of soybean. According to the results of some authors, under field conditions, growth of faba bean and mungbean increased significantly in response to inoculation with the most effective rhizobial strains $(25,26)$.

Number of nodules of mungbean increased in both the Rhizobium 3 and Rhizobium 9 inoculation. Rhizobium 3 had a positive significant effect on the number of nodules per plant that the maximum the number of nodules per plant was obtained from inoculation with Rhizobium 3 treatment by 52 nodules that the number of nodules per plant increased by $8 \%$ as compared with Rhizobium 9 treatment (Figure).

Table.1 Effect of microbial preparations on plant height, root length and plant weight of mungbean in field conditions

\begin{tabular}{|l|c|c|c|c|}
\hline Treatments & $\begin{array}{c}\text { Plant height } \\
(\mathbf{c m})\end{array}$ & $\begin{array}{c}\text { Root length } \\
(\mathbf{c m})\end{array}$ & $\begin{array}{c}\text { Shoot dry } \\
\text { weight }(\mathbf{g})\end{array}$ & $\begin{array}{c}\text { Root dry } \\
\text { weight }(\mathbf{g})\end{array}$ \\
\hline Control & $41.20 \pm 1.57$ & $12.40 \pm 2.29$ & $6.72 \pm 0.42$ & $0.38 \pm 0.02$ \\
\hline PlantaStim & $42.00 \pm 2.02$ & $12.60 \pm 1.00$ & $10.61 \pm 0.46^{*}$ & $0.44 \pm 0.05$ \\
\hline Rhizobium 3 & $55.80 \pm 1.69^{*}$ & $22.00 \pm 1.86^{*}$ & $15.64 \pm 0.69^{*}$ & $0.68 \pm 0.08^{*}$ \\
\hline Rhizobium 9 & $52.40 \pm 2.02^{*}$ & $22.60 \pm 2.20^{*}$ & $15.14 \pm 0.66^{*}$ & $0.57 \pm 0.05^{*}$ \\
\hline
\end{tabular}

Level of significance, $*(\mathrm{P}<0.05)$.

Table.2 Effect of microbial preparations on number of pod per plant, length of pod and weight of pod per plant of mungbean in feild conditions

\begin{tabular}{|c|c|c|c|}
\hline Treatments & $\begin{array}{c}\text { Pod } \\
\text { plant }^{-1}(\text { no. })\end{array}$ & $\begin{array}{l}\text { Pod length } \\
\quad(\mathrm{cm})\end{array}$ & $\begin{array}{c}\text { Pods weight } \\
\text { plant }^{-1}(g)\end{array}$ \\
\hline Control & $11.80 \pm 0.84$ & $7.98 \pm 1.62$ & $5.60 \pm 0.40$ \\
\hline PlantaStim & $14.80 \pm 1.42$ & $8.76 \pm 1.31$ & $7.87 \pm 0.73$ \\
\hline Rhizobium 3 & $23.00 \pm 0.62 *$ & $10.58 \pm 0.67 *$ & $17.97 \pm 2.01 *$ \\
\hline Rhizobium 9 & $24.60 \pm 3.31$ & $10.57 \pm 0.53$ & $18.45 \pm 2.03$ \\
\hline
\end{tabular}


Table.3 Effect of microbial preparations on number of seed per plant, number of seed per pod, weight of seed per plant and weight of 1000 seed of mungbean in feild conditions

\begin{tabular}{|c|c|c|c|c|}
\hline Treatments & $\begin{array}{c}\text { Seed } \\
\text { plant }^{-1}(\text { no. })\end{array}$ & $\begin{array}{c}\text { Seed } \\
\operatorname{pod}^{-1}(\text { no. })\end{array}$ & $\begin{array}{c}\text { Seed weight } \\
\text { plant }^{-1}(g)\end{array}$ & $\begin{array}{l}1000 \text { seed } \\
\text { weight }(g)\end{array}$ \\
\hline Control & $90 \pm 7.72$ & $7.60 \pm 0.82$ & $4.89 \pm 0.45$ & $54.40 \pm 2.20$ \\
\hline PlantaStim & $116 \pm 11,17 *$ & $7.79 \pm 1.11$ & $6.57 \pm 0.22 *$ & $57.00 \pm 3.92$ \\
\hline Rhizobium 3 & $210 \pm 14.09 *$ & $9.11 \pm 0.35^{*}$ & $14.91 \pm 1.98 *$ & $71.20 \pm 3.89 *$ \\
\hline Rhizobium 9 & $234 \pm 10.41 *$ & $9.70 \pm 0.56$ & $16.31 \pm 1.24 *$ & $69.70 \pm 3.79 *$ \\
\hline
\end{tabular}

Fig.1 Effect of rhizobial preparations inoculation on number of nodules of mungbean

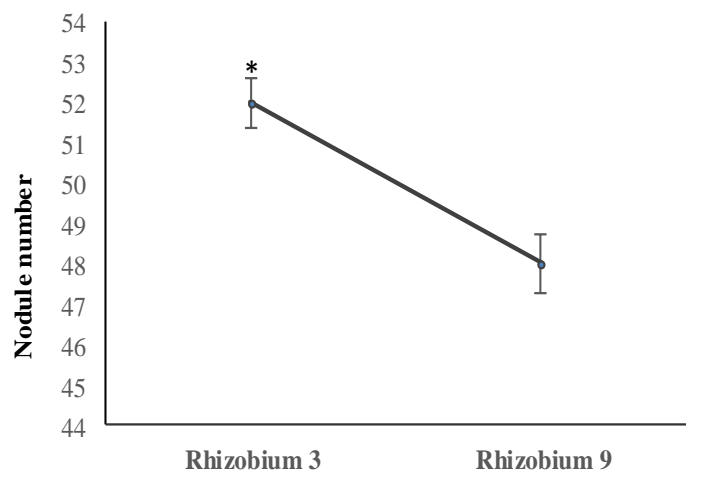

The rhizobial inoculation with its considerable positive effects showed increases the number of nodules per plant. Similar findings were reported for bean (27), soybean (16), munbean (28) and chickpea (29). According to the results of some authors, $B$. japonicum strains improved soybean nodulation, and increased nitrogen fixation (17, 30). Dhami and Prasad (24) reported that inoculation of soybean plants with $B$. japonicum increased nodule number. Raza et al., (19) reported on mungbean when inoculated with Rhizobium strain increased the number of nodules of mungbean.

PlantaStim preparation inoculation increased the number of pods per plant by $25 \%$, weight of pods per plant by $40 \%$, number of seed per plant by $28 \%$ and weight of seed per plant by $34 \%$ compared to control (Table 2, 3). The results showed that Rhizobium 3 and Rhizobium 9 had a positive significant effect on the number of pods per plant that the maximum the number of pods per plant was obtained from inoculation with Rhizobium 9 treatment by 24.60 pods that the number of pods per plant increased by $108 \%$ as compared with control treatment (Table 2). Rhizobium 9 inoculation significantly increased the length of pod by $32 \%$, seed per pod by $27 \%$ and 1000 seed weight by $28 \%$ compared to control. Inoculation with Rhizobium 3 significantly increased the length of pod and 1000 seed weight compared other 
treatments. The maximum 1000 seed weight was obtained from inoculation with Rhizobium 3 treatment of by 71.20 seed weight by $30 \%$ compared to control treatment.

Rhizobium 3 and Rhizobium 9 preparations used in this study have improved yield compounds of mungbean in field conditions. Similar results were reported by Dhami and Prasad (24). Rhizobium sp. improved the number of pods, the number of grains, the weight of pods, the weight of grains, 100 and 1000 grains weight of several legumes such as soybean $(12,24,20,6,16)$, chickpea (31) and mungbean $(32,15,18)$. Raza et al., (19) reported that Rhizobium inoculation increased seed weight per plant by $64 \%$ compared to uninoculated control. Delic et al. (23) observed that the B. japonicum strain 542 inoculation increased the grain yield of mungbean in field conditions.

In conclusion, our work demonstrated that inoculation with Rhizobium 3 and Rhizobium 9 preparations could enhance formation of nodules on mungbean grown in field conditions. In summary, a significant positive effect of inoculation with Rhizobium 3 and Rhizobium 9 preparations, on plant growth, nodulation and yield of mungbean in field conditions. The Rhizobial preparations could be the most suitable inoculant preparations for mungbean cultivation practices.

\section{Acknowledgement}

This work has been financed by the Ministry of Innovational Development of the Republic of Uzbekistan.

\section{References}

1. Khan A and Mailik MA, Determing biological yield potential of different mungbean cultivars. J Biol Sci, 1 (2001)
575.

2. Razzaque MA, Haque MM, Karim MA and Solaiman AR, Nitrogen fixating ability of mungbean genotypes under different levels of nitrogen application. Bangladesh J Agril Res, 41 (2016) 163.

3. Arora NK, Kang SC and Maheshwari DK, Isolation of siderophore-producing strains of Rhizobium meliloti and their biocontrol potential against Macrophomina phaseolina that causes charcoal rot of groundnut. Curr Sci, 8 (2001) 673.

4. Tilak K, Ranganayaki $\mathrm{N}$ and Manoharachari C, Synergistic effects of plant-growth promoting rhizobacteria and Rhizobium on nodulation and nitrogen fi xation by pigeon pea (Cajanus cajan). Eur J Soil Sci, 57 (2006) 67.

5. Saha R, Saha N, Donofrio RS and Besterbelt LL, Microbial siderophores: a mini review. J Basic Microbiol, 52 (2012) 1 .

6. Masciarelli O, Llanes A and Luna V, A new PGPR co-inoculated with Bradyrhizobium japonicum enhances soybean nodulation. Microbiological Research, 169 (2014) 609.

7. Jabborova D and Davranov K, Effect of phosphorus and nitrogen concentrations on root colonization of Soybean (GLYCINE MAX L.) by Bradyrhizobium japonicum and Pseudomonas putida. International Journal of Advanced Biotechnology and Research(IJBR), 6 (2015) 418.

8. Egamberdieva D, Jabborova D and Berg G, Synergistic interactions between Bradyrhizobium japonicum and the endophyte Stenotrophomonas rhizophila and their effects on growth and nodulation of soybean under salt stress. Plant and Soil, 405 (2016) 35.

9. Egamberdieva D, Jabborova D, Wirth S, Alam P, Alyemeni $\mathrm{MN}$ and Ahmad P, Interaction of magnesium with nitrogen and phosphorus modulates symbiotic performance of soybean with 
Bradyrhizobium japonicum, and its root architecture. Frontiers in Microbiology, 9 (2018) 1.

10. Carter J M, Gardner W K and Gibson A H, Improved growth and yield of faba beans (Vicia faba cv. fiord) by inoculation with strains of Rhizobium leguminosarum biovar. viciaein acid soils in south-west Victoria. Aust J Agric Res, 94 (1994) 613.

11. Elsheikh EAE and Elzidany AA, Effects of Rhizobium inoculation, organic and chemical fertilizers on yield and physical properties of bean seeds. Plant Foods Human Nutr, 51 (1997) 137.

12. Egamberdiyeva D, Qarshieva D and Davranov K, The use of Bradyrhizobium japonicum to enhance growth and yield of soybean varieties in Uzbekistan conditions. J Plant Growth Regul, 23 (2004) 54.

13. Hadi EA and Elsheikh EAE, Effect of rhizobium inoculation and nitrogen fertilization on yield and protein content of six chickpea (Cicer arietinum L.) cultivars in marginal soils under irrigation. Nutr Cycl Agroecosyst, 54 (1999) 57.

14. Yadegari $\mathrm{M}$ and Rahmani HA, Evaluation of bean (Phaseolus vulgaris) seeds' inoculation with Rhizobium phaseoli and plant growth promoting Rhizobacteria (PGPR) on yield and yield components. African Journal of Agricultural Research, 5 (2010) 792.

15. Kashem MA, Mian MH and Rahman MF, Effect of Bradyrhizobium on the yield of mungbean (Vigna radiata L.) grown in Ganges Tidal floodplain soil. J Agric Res, 38 (2000) 407.

16. Mukhtar MAE, Effect of overexpression of AtPAP15 on soybean-arbuscular mycorrhizal fungi/Rhizobium symbiosis and abiotic stress, Ph.D. thesis, South China Agricultural University, Guangzhou, 2015.

17. Daramola DS, Danso SKA and Hardarson $\mathrm{G}$, Nodulation, $\mathrm{N}_{2}$ fixation and dry matter yield of soybean [Glycine Max (L.)
Merrill] inoculated with effective and ineffective Bradyrhizobium japonicum strains. Soil Biochem, 26 (1994) 883.

18. Sharma S, Growth, physiological and yield aspects of mungbean (Vigna radiata) as affected by inoculation treatment by different strains of Bradyrhizobium culture. I J Res Crop, 2 (2001) 112.

19. Raza W, Akhtar M, Arshad M \&Yousaf S, Growth, nodulation and yield of mungbean (Vigna radiata L.) as influenced by coinoculation with rhizobium and plant growth promoting rhizobacteria. Pak J Agri Sci, 41 (2004) 125.

20. Egamberdieva D, Jabborova D \&Wirth S, Alleviation of salt stress in legumes by coinoculation with Pseudomonas and Rhizobium. Plant Microbe SymbiosisFundamentals and Advances, (2013) 4.

21. Egamberdieva D, Wirth S, Jabborova D, Räsänen LA and Liao $\mathrm{H}$, Coordination between Bradyrhizobium and Pseudomonas alleviates salt stress in soybean through altering root system architecture. Journal of Plant Interactions, 12 (2017) 100.

22. Youseif SH, Abd El-Megeed FH, Khalifa MA and Saleh SA, Symbiotic effectiveness of Rhizobium (Agrobacterium) compared to Ensifer (Sinorhizobium) and Bradyrhizobium genera for soybean inoculation under field conditions. Res. J. Microbiol, 9 (2014) 151.

23. Delic D, Stajkovic-Srbinovic O, Kuzmanovic D, Rasulic N, Mrvic V, Andjelovic S and Knezevic-Vukcevic J, Effect of bradyrhizobial inoculation on growth and seed yield of mungbean in Fluvisol and Humofluvisol. African Journal of Microbiology Research, 5 (2011) 3946.

24. Dhami N \&Prasad BN, Effect of Bradyrhizobium japonicum on biomass and crop yield of soybean [Glycine Max (L.) Merr.]. Journal of Microbial World, 8 (2006) 15. 
25. Sharma $P$ and Khurana AS, Effect of single and multi-strain Rhizobium inoculants on biological nitrogen fixation in summer mungbean, Vigna radiata (L.) Wilczek. Res Dev Rep, 14 (1997) 8.

26. Youseif SH, Abd El-Megeed FH and Saleh SA, Improvement of faba bean yield using rhizobium/agrobacterium inoculant in lowfertility sandy soil. Agronomy, 7 (2017) 1.

27. Daba $S$ and Haile M, Effects of rhizobial inoculant and nitrogen fertilizer on yield and nodulation of common bean. $J$ Plant Nutr, 23 (2000) 581.

28. Hafeez FY, Hameed $\mathrm{S}$, Ahmad $\mathrm{T}$ and Malik KA, Competition between effective and less effective strains of Bradyrhizobium spp. for nodulation on Vigna radiata. Biol. Fertil. Soils, 33 (2001) 382.

29. Ben Romdhane S, Tajini F, Trabelsi M, Aouani $\mathrm{M}$ and Mhamdi R, Competition for nodule formation between introduced strains of Mesorhizobium ciceri and the native populations of rhizobia nodulating chickpea (Cicer arietinum) in Tunisia. World J Microbiol Biotechnol, 23 (2007) 1195.

30. Zhang H, Prithiviraj B, Charles T C, Driscoll B T and Smith D L, Low temperature tolerant Bradyrhizobium japonicum strains allowing improved nodulation and nitrogen fixation of soybean in a short season (cool spring) area. Europ. J. Agronomy, 19 (2003) 205213.

31. Sattar MA, Quader MA and Danso SKA, Nodulation, nitrogen fixation and yield of chickpea as influenced by host cultivar and Bradyrhizobium strain differences. Soil Biol Biochem, 27 (1995) 725.

32. Thakur AK and Panwar JDS, Effect of Rhizobium -VAM interactions on growth and yield in mungbean (Vigna radiata $\mathrm{L}$.) under field conditions. Indian $J$ Plant Pathol, 38 (1995) 62.

\section{How to cite this article:}

Farrukh Matkarimov, Dilfuza Jabborova and Saidmurot Baboev. 2019. Enhancement of Plant Growth, Nodulation and Yield of Mungbean (Vigna radiate L.) by Microbial Preparations. Int.J.Curr.Microbiol.App.Sci. 8(08): 2382-2388. doi: https://doi.org/10.20546/ijcmas.2019.808.277 